and when opened, on September 6, it presented a gruesome spectacle. The magnets were covered with rust, the wood-work was swollen and would not fit the joints for which it was intended, the wires in the eyepieces missing, silvered mirrors spoilt, and other horrors which it can be imagined scientific apparatus would present after such treatment. All the damages had to be remedied on the spot by their own ingenuity, while, to add to their distress, they lost by the upset much of their petroleum, and had to reduce their light. Nevertheless, in the early days of November, all repairs were effected and the instruments reacly for worl.

The results of the expedition are practically divided into three parts. In the first, which is more especially under the superintendence of $\mathrm{M}$. V. Fuss, are given the description of the method and the results of the observations at numerons stations for the determination of geographical position. These observations have not been made with that rigorous accuracy to which we are accustomed in inquiries that have for their aim the discussion of the variations of latitude. They are rather field observations, made with the sextant, and instruments possessing similar accuracy, and are no doubt very useful in constructing maps of a practically unknown country. In the same way with the longitude determinations, there is no electrical communication between these places, of which Jakutsk is possibly the only one that would be recognised by the ordinary English reader. A few box chronometers were carried from station to station to determine the difference of local time. Moon culminations and occultations were also employed, and, strange to say, eclipses of Jupiter's satellites. Nothing is said about the errors of the tables or the corrections that have been applied to remove those errors, but the results agree fairly well with other methods. Possibly those observations only have been used, which coincided with others made in a known longitude : bu since the whole chain is made to depend for absolute longitude on that of a station at Jakutsk, determined on the occasion of the eighteenth century transits of Venus, and now unrecognisable, they do not probably interfere much with the final accuracy. The outcome of the inquiry is to give us more or less trustworthy positions of some twenty-four stations ranging between $8 \mathrm{~h}$. $-9 \mathrm{~h}$. east longitude from Greenwich, and from $60^{\circ}-74^{\circ}$, north latitude.

In the next section, under the superintendence of MM. N. Juirgens and F. Miiller, are presented the results of the magnetical observations. M. Misller's part is more particularly confined to derising the elements of the earth's magnetism at a considerable number of stations, all in North-East Siberia, by a few observations of the declination, dip, and horizontal force at each. M. Jiirgens took charge of the Ssagastyr station, where, in greater detail, he sought not only the absolute force, but the hourly variation of the magnetic elements. M. Muiller, as his share, is able to present a table in which, for seventeen stations, the three elements have been fairly well determined, while in twenty-eight more or less complete observations have been made. From November I 882 to June I 884 , M. Jürgens' department made hourly observations of the declination, and of the horizontal and vertical force, and on selected days observations at every five minutes. The instruments appear to have been critically examined, and the results of an inquiry conducted so far away from beaten tracks possesses a special interest.

Advantage was taken of the peculiar position to make some observations on the aurora as to its form, colour, direction, and altitude. These will be found in what may be called the third section, together with the history of the expedition written by Dr. A. Bunge, wherein will be found many interesting remarks on a country but little known. The climate, the native inhabitants, the flora and fauna of the district, all come more or les under his observant notice, and are treated easily and pleasantly.

In the second work the element of adventure is, of course, wanting, and, with greater ease, Dr. Palazzo has been able to collect his data from various points on the Italian Peninsula, in such a way as to present a tolerably complete magnetic survey of the whole country. A chain of stations has been selecled, starting from Rome and proceeding south-east past Naples towards Brindisi. Other positions have been occlipied on the Adriatic coast, including one in the Tremiti Isles; while another group occupies the north-east, and includes Venice, Ravenna, and other well-known places. The entire series includes twenty-two stations. Dr. Palazzo has devoted great attention to the form of his instruments, and has been alive to the importance of deriving the instrumental constants with accuracy. His method of procedure is set out at NO. I 374 , VOL. 53 length in the first part of his paper. In the second part, the details of his observations are given. On the average, these do not extend over more than two or three days at each station, which have sufficed for the determination of the declination by observing azimuths of the sun. The horizontal force has been obtained by the method of counting the number of oscillations made by the magnet in a given time. These in connection with the dip, also derived at each of the stations, have permitted him, in the usual method, to derive the vertical force and total intensity. The whole operation and deductions are conveniently exhibited in symmetrically arranged tables.

\section{THE MOVEMENTS OF THE TERRESTRIAL POLE DURING THE YEARS I890-95.}

TOWARDS the latter end of last year Prof. Albrech gave a preliminary account of the, then, known movements of the terrestrial pole at the eleventh general conference of the "International Erdmessung." Since that date he has made a more definite investigation, the results of which will be published in the Verhandlunsen der Berliner Conferenz; but as this will not just yet appear, he gives in the current number of the Astr. Nach. (No. 3333) a brief summary of the results.

The observations have been made at several observatories, namely, Kasan, Pulkowa, Prag, Berlin, Bamberg, Kiel, Karlsruhe, Strassburg, New York (Columbia College), and Bethlehem, also at the Military Geographical Institute in Vienna, the

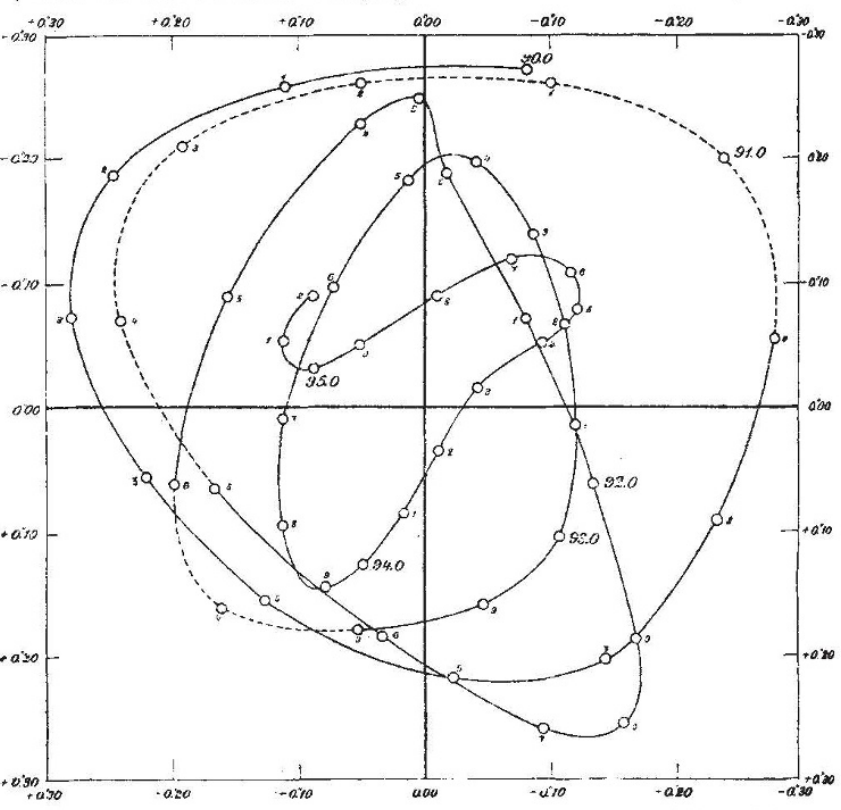

Curve showing the relation between the mean and cpparent positions of the pole during the years $1890-95$

Geodetic Institute in Potsdam, and at the American Coast and Geodetic Survey.

Prof Albrech has not, however, used all the observations in the discussion, but enough "um den Versuch einer Ableitung der Bahn des Pols für den ganzen fünfjährigen Zeitraum mit Aussicht auf Erfolg durchfiihren zu konnen."

The method of computation adopted was somewhat analogous to that employed by Kostinsky in I893. Commencing with the monthly observed mean from each station, the deviations $\left(\phi-\phi_{0}\right)$ of the instantaneous pole elevations from a very accurate mean value were graphically formed for every tenth part of the year ; a system of coordinates was also arranged in which the positive-axis of $x$ pointed towards Greenwich, that of y $90^{\circ}$ to the westward, the origin coinciding with the mean position of the pole.

In this way Prof. Albrech obtained a series of points, which, when plotted out and connected together by means of a curve, would show the relation of the position of the terrestrial pole, at any moment during the interval covered by the observations, to its mean position.

The accompanying curve is a reproduction of that given by Prof. Albrech. 
It will be seen that the curve commences moving round the origin of coordinates, gradually closing up, and becoming more elongated in form, the difference between its instantaneous and mean positions decreasing up to 1895 very perceptibly. The dotted path is traced through points which have been interpolated, and which could not be directly obtained owing to insufficiency of observations.

The general trend of the plotted points indicates an unmistakable decrease in the amplitude during the five years of observation, and, as Prof. Albrech points out, the movement is by no means simple, but necessitates the presence of more terms in the expression for representing this motion.

The communication concludes with a table giving the values for every $30^{\circ}$ of longitude of the terms

$$
\begin{aligned}
& x \cos \lambda+y \sin \lambda \\
& y \cos \lambda-x \sin \lambda
\end{aligned}
$$

for the different epochs in connection with the three equations for calculating the variations in the altitude, azimuth, and longitude, namely,

$$
\begin{gathered}
\phi-\phi_{0}=+x \cos \lambda+y \sin \lambda \\
a-\alpha_{0}=+(y \cos \lambda-x \sin \lambda) \sec \phi \\
\lambda \quad \lambda_{0}=-(y \cos \lambda-x \sin \lambda) \tan \phi
\end{gathered}
$$

\section{UNIVERSITY AND EDUCATIONAL INTELLIGENCE.}

Cambridge.-Prof. J. J. Thomson, F.R.S., has been appointed Rede Lecturer for the present year.

The Natural Sciences Tripos will begin on May 27, and the various practical and oral examinations will not be concluded until J une 16.

Prof. Ramsay, F.R.S., has been appointed an Elector to the Jacksonian Professorship of Natural Philosophy, now held by Prof. Dewar, F.R.S.

A meeting of members of the Senate, presided over by the Provost of King's, was held on Saturday last, at which resolutions were passed unanimously in favour of granting a titular recognition (such as an honorary B.A.) to qualified women, and against conceding anything that might lead to the transformation of Cambridge into a "mixed" University.

Sir Henry Roscoe has been elected Vice-Chancellor of the University of London, in the place of the late Sir Julian Goldsmid. Mr. F. V. Dickins, the Assistant-Registrar, has been elected Registrar, in the place of Mr. A. Milman, retired.

WE have received a combined Calendar, History, and General Summary of Regulations of the Department of Science and Art (1896). From the statistics therein given it appears that there are 2889 Science and Art Schools in the United Kingdom, and that they contain among them 167,822 students in science classes, and 132,256 students in art classes.

THE fourth annual Report of the Technical Instruction SubCommittee of the City of Liverpool, which deals with the work accomplished by them during 1895 , is eminently satisfactory. Abundant evidence is furnished that great things have been accomplished in Liverpool during the past year. Preliminary steps have been taken towards the erection of a central institution for the accommodation of evening science and technological classes. Three organised day science schools have been established; and a school of applied arts has been called into existence. An electro-technical department, evening courses of advanced work in the engineering laboratories, a special department deaiing with the science and art of education, have all grown up at the University College of the city as a result of the assistance given by the Technical Instruction Sub-Committee. But the difficulty arising from insufficient previous education, which is hampering the work of similar Committees in all parts of the country, is very much felt in Liverpool. The Chairman reports: "Institutions which were founded to give a strictly technical education have had, in many cases, to enlarge their borders, and provide preparatory departments or classes, in which to prepare students, by a general preliminary training, to take proper advantage of the special technical teaching." We cordially commend the following decision of the Liverpool Committee to all whom it may concern : "Partly on this ground, but still more from a conviction that the best preparation for commercial pursuits - the staple 'inclustry' of Liverpool-is to be found in a thoroughly good modern general education, the Committee have sought to encourage and assist the public secondary schools of the city to adapt themselves to give such an education."

The variegated nature of the technical education which has been developed throughout the country as a result of the Acts dealing with the question, is strikingly apparent to us each lime we receive a new report. Though that of Liverpool is so satisfactory as a whole, its list of "technical" subjects emphasises this point yet again. On p. 49 of the Technical Instruction Committee's report, we find they encourage the teaching (amongst a large number of other subjects) of singing and musical notation, instrumental music, type-writing, tailors work, cabinet-making, ship carpentry and joinery, and so on. The extraordinary thing is, in view of the express clause of the Technical Instruction Act, I889, "that technical instruction shall not include teaching the practice of any trade or industry, or employment," that the Science and Art Department should sanction such subjects as these.

\section{SCIENTIFIC SERIALS.}

Bulletin de la Sociétes des Naturalistes de Moscou, I895, No. I.--The vascular cryptogams of the Middle Urals and the surrounding territory, by P.W. Ssiisew (in German). The fern which freely grow in the shadow of the pine forests of the Urals, make a substantial and most picturesque part of the flora of the country. The most common species are :-Poly podium dryopteris, Phegopteris polypodiodides, Athyrium filix femina, Asplenium crenatum, Aspidium spinulosum, \&c. In the stony parts of the highlands one finds the elegant species of Allosurus, Woodsia, Asplenium ruta muraria, A. viride, A. septentrionale, and many others, which disappear already at short distance from the Ural range, although the conditions for their growth seem to be the same. Latest research has shown that only three species, characteristic of the Northern Urals, do not appear in the middle and southern parts of these mountains. Forty-seven different species are described.-On adhesion between metals, glass, and different other substances, by J. Weinberg (German). The observations of $M$. Charles Margot are discussed, and the atthor shows that the different degrees of adhesion between different substances agree with his molecular formula. - From the shores of the Mediter. ranean, by H. Trautschold (in German). The structure of the conglomerates and other deposits on the shores of the Mediterranean Sea at Nizza is discussed in order to show that the phenomena are best explained by a retreat of the sea, but do not agree with an upheaval of the coast. Lanius eleagni, a new species, akin to Otomela Bogdanozvii, Bianchi, by P. Suschkin.-The tail-organ of the Raja, by N. Iwanzoff (in German), with three plates. 1)etailed anatomical work, in which the difficulties that the useudoelectrical organs of fishes are supposed to offer to Darwin's theory are discussed and explained. - On the Libelintidece of Poltava and Kharkov, by V. N. Roozianko (in Russian). Fourteen species are described.-Catalogue of the fungi of Smolensk, by A. A. Jaczewski (in Russian). Two hundred and fifty-four species are enumerated. The author makes the remark that the forests are extremely rich in species of lizssula, and that all the species of this genus, without exception, are used for food by the peasants, but that cases of poisoning are never heard of. He makes the suggestion that perhaps the poisonous species, Reussuía emetica and $R$. rubra, are very rare (each was found only once); but altogether it must be supposed that the manner of cooking destroys their poisonous properties, if they exist-a question which well deserves scientific investigation. - List of members.

Bollettino della Sociutì Sismologica Italiana, vol, i., 1896, No. 8 . - The Cecchi microseismograph, by G. Giovannozzi. The first description of the instrument published in a scientific journal.Hydrothermal observations at Fiumecaldo (Catania) in May and June 1895 , by C. Ciuzzanti. - Notices of Italian earthquakes (June-July 1895), the more important being the Venetian and Lubiano earthquakes of June IO, and the disastrous earthquake which occurred on the east coast of the Caspian Sea during the night of July 8-9. Copies of two of the microseismographic records of the latter earthquake obtained at Rome are given.

No. I 374 , VOL. 53] 